\title{
O olhar estereoscópico para a ontogênese: desafiando o professor
}

\author{
Elena Gorlova \\ Organização Não Governamental Autônoma de Educação Básica \\ Escola Internacional Vnukovo, Moscou, Rússia, $R U$
}

\begin{abstract}
Resumo
O presente artigo tem como objetivo examinar como é possivel ao professor - ou ao adulto-educador - estruturar um sistema de meios culturais conjugado com a idade psicológica da criança que possa operar sobre a zona de desenvolvimento iminente da criança. Para tanto, analisa-se o potencial metodológico da abordagem histórico-cultural de Vigotski para o diagnóstico e a promoção do desenvolvimento psíquico de crianças no início da vida escolar. Argumenta-se que, para o diagnóstico do desenvolvimento e a definição de estratégia do trabalho corretivo, é importante manter um olhar estereoscópico em que os eixos das coordenadas da visão ampla da criança sejam: o conteúdo da relação de convivência com os adultos e coetâneos, as especificidades da neoformação psicológica da idade como o conteúdo da vontade e do desenvolvimento cultural e, finalmente, a função psíquica central e a atividade-guia. São descritos dois exemplos que permitem indicar os aspectos corretivos centrais do adulto-educador e delinear prognósticos.
\end{abstract}

Palavras-chave: zona de desenvolvimento iminente; neoformação psicológica; função volitiva.

\section{The stereoscopic look at ontogenesis: challenging the teacher}

\begin{abstract}
This article aims to examine how it is possible for the teacher - or the adult educator - to structure a system of cultural media combined with the child's psychological age that can operate on the child's imminent development zone. So, the methodological potential of Vygotsky's historical-cultural approach to the diagnosis and promotion of children's psychic development at the beginning of school life is analyzed. It is argued that, for the diagnosis of development and the definition of corrective work strategy, it is important to maintain a stereoscopic view according to which the axes of the child's broad view coordinates are: the content of the living relationship with adults and contemporaries, the specifics of the psychological neoformation of age as the content of will and cultural development, and finally the central psychic function and guiding activity. Two examples are described that allow us to indicate the central corrective aspects of the adult educator and to outline prognoses.
\end{abstract}

Keywords: imminent development zone; psychological neoformation; volitional function.

Lev Semionovitch Vigotski é predominantemente conhecido na psicologia estrangeira como autor do conceito de zona de desenvolvimento iminente. De acordo com a sua definição, o conceito significa o nível de complexidade de tarefas que a criança não consegue resolver de forma autônoma, mas o faz na convivência com o adulto.

O nível de complexidade das tarefas é dado pela idade psicológica da criança, ou seja, pelo conteúdo das neoformações psicológicas da idade e do tipo de atividade-guia. A qualidade do auxílio do adulto relaciona-se com ação pelo fato de ele saber estruturar, voluntaria e conscientemente, o contexto de relação de convivência de acordo com a idade psicológica da criança, ocupando diferentes posições na relação.

No trabalho de Kravtsova, Kravtsov e Berejkovskaia (2007), foram destacadas 5 posições: 1) a posição independente na relação de convivência; 2) a posição de "proto-nós" (de comunalidade psicológica); 3) a posição "acima de" (de quem ensina, de quem sabe); 4) a posição "abaixo de" (de quem não sabe, de quem pergunta); 5) A posição de iguais como uma alternância dinâmica de "acima de" e "abaixo de". A posição "de igualdade", já

\footnotetext{
^Endereço para correspondência: General Education Autonomous Nonprofit Organization - International School Vnukovo. Russian Federation. Moscow, Pervomaiskoe Settlement, Rogozinino Village, Lugovaya Street 20B. 108808. E-mail: gorlova.e@rggu.ru

Os dados completos da autora encontram-se ao final do artigo.
}

dominada pela criança, inclui o saber manter o contexto comum e o objetivo da relação, de combinar a respeito da distribuição de funções e papéis.

A criança na idade escolar inicial (levando-se em conta não a idade da certidão de nascimento, mas a psicológica) domina todas as posições na relação de convivência com os adultos e com seus coetâneos. Isso significa que, nessa idade, o adulto não é o único que pode propiciar a zona de desenvolvimento iminente, mas também uma criança mais velha ou um coetâneo que conheça e saiba mais.

L. S. Vigotski (1996b) utiliza o termo "duas linhas da ontogênese infantil" - a linha natural (biológica, natural) e a linha cultural (volitiva) do desenvolvimento da criança. Em seus textos, essas duas linhas formam uma unidade complexa. Em cada etapa da ontogênese, estruturam-se determinadas ligações entre essas duas linhas, ou sistemas de atividade psíquica (orgânica e instrumental), essencialmente.

Ao destacar as duas linhas do desenvolvimento, L. S. Vigotski introduz o conceito de "desenvolvimento das funções psíquicas superiores". Ele é apresentado na citação abaixo:

[...] duas ramificações principais, dois fluxos do desenvolvimento das formas superiores de comportamento que estão interligados de modo indissolúvel, mas nunca se fundem num todo único. São, primeiramente, processos de domínio dos meios externos do desenvolvimento cultural e do pensa- 
mento - a língua, a escrita, o cálculo, o desenho. Em segundo lugar, são processos de desenvolvimento de funções psíquicas superiores especiais, não delimitadas e determinadas com precisão, denominadas, na psicologia tradicional, de atenção voluntária, memória lógica, elaboração de conceitos, etc. Ambas formam o que convencionamos denominar de processo de desenvolvimento das formas superiores de comportamento da criança (VIGOTSKI, 1996a, p. 241).

$\mathrm{Na}$ abordagem histórico-cultural, o estudo das ligações existentes entre as funções, a formação de novos sistemas psicológicos são "o alfa e o ômega" da busca científica.

Atualmente, a história do desenvolvimento das funções psíquicas superiores adquire um significado especial em função dos trabalhos do professor e doutor em psicologia G. G. Kravtsov (2006, 2012). Ele relaciona o desenvolvimento cultural da criança com o desenvolvimento da vontade que, em cada idade, se materializa como uma neoformação psicológica central da idade. Na concepção histórico-cultural, esse é o critério fundamental para definir os períodos de desenvolvimento e a idade psicológica da criança.

Em cada idade, na colaboração com o adulto, emerge, inicialmente, no centro do desenvolvimento, a função volitiva superior (social por sua origem), que define a linha do desenvolvimento cultural da criança. Essa função volitiva é a neoformação psicológica da idade, é o meio psicológico do desenvolvimento da personalidade. Nesse momento, o caráter instrumental do desenvolvimento manifesta-se no fato de a neoformação psicológica da idade se formar nas relações com os adultos. Posteriormente, a função volitiva da consciência já dominada pela criança estabelece relações complexas com processos naturais e psicofisiológicos e as transforma em superiores, voluntárias.

Conhecendo o conteúdo da neoformação psicológica da idade, em cada período do desenvolvimento, bem como as funções psíquicas-chave (naturais por sua origem), podemos estabelecer prioridades avaliativas para a prestação de ajuda psicológica.

Assim, o profissional pode, voluntariamente, estruturar um sistema de meios culturais conjugado com a idade psicológica da criança. Esses meios podem prover a zona de desenvolvimento tanto da criança quanto do adulto de sua convivência mais próxima.

Assim, para o diagnóstico do desenvolvimento e a estratégia do trabalho corretivo é importante manter um "olhar estereoscópico", em que os eixos das coordenadas da visão ampla da criança são: o conteúdo da relação de convivência (posição, contexto) com os adultos e coetâneos, as especificidades da neoformação psicológica da idade como o conteúdo da vontade e do desenvolvimento cultural e, finalmente, a função psíquica central e a atividade-guia.

Antes do limiar da primeira idade escolar, a criança começa a dominar algumas funções volitivas e, em primeiro lugar, a fala e a imaginação. Esses instrumentos, por sua vez, garantem a formação da percepção significativa de objetos, na primeira infância (mediada pela fala).
Ao final da idade pré-escolar, a imaginação incorpora-se à esfera afetiva e transforma as emoções em sentimentos controlados pela consciência da criança.

Na primeira idade escolar, o conteúdo da zona de desenvolvimento iminente da neoformação psicológica da idade é a estruturação voluntária de situações diversificadas do tipo "figura-fundo" (atenção voluntária).

Incialmente, em colaboração com o adulto, a criança adquire a aptidão para a troca e a manutenção dessas estruturas da consciência, como o sentido da situação e seu conteúdo material. O sentido é infinitamente diverso e multifacetado. O conteúdo do objeto está dado e definido do mesmo modo e é universal.

Na subcultura da primeira idade escolar, há problemas para orientar a atenção voluntária que ilustram a movimentação da criança entre o sentido e o significado. Eis uma delas.

Uma menina órfã está sentada no fundo do poço, chorando tristemente. Um diabinho se aproxima dela e diz: "Menina, menina, deixe eu te ajudar a sair daí, mas terá que me enviar, em substituição a você, sua mãe ou seu pai". Quem a menina enviará e por quê?

Partindo do sentido pessoal, haverá tantas respostas quantos respondentes. Porém, existe apenas uma resposta precisa, que decorre das condições do problema. Inicialmente, as crianças apresentam uma multiplicidade de variantes, fundamentadas em suas experiências e imaginação. Por exemplo, elas consideram que a menina enviará em seu lugar a mãe, porque a mãe não cuidou dela e, por isso, caiu no poço. Numa nova versão, dizem que é o pai, porque ele é muito rígido e a menina se escondeu dele no poço, etc. Normalmente, depois de ouvir o mesmo problema pela segunda vez, as crianças na primeira idade escolar resolvem essa história corretamente (a menina é órfã).

A seguir, apresentamos outro exemplo que também tem um recurso diagnóstico e corretivo.

O problema se chama "História desenhada" (KRAVTSOVA; KRAVTSOV; BEREJKOVSKAIA, 2007). O adulto e a criança precisam fazer um desenho numa única folha, sem discutir seu conteúdo e combinando entre si quem começará. Eles precisam desenhar alternadamente e criar um cenário comum para a história.

Ao término do desenho, propõem-se aos participantes algumas tarefas relativas ao que fizeram:

1) inventar e escrever o título do desenho, separadamente e em segredo, sem comentar com o parceiro;

2) perguntar ao parceiro quem, em sua opinião, é o protagonista no desenho e o que ele faz. Eles podem mostrar seu desenho a outro par de participantes "adulto-criança", propondo-lhes que inventem uma resposta à pergunta sobre o desenho, o que irá acontecer dali para frente ou o que aconteceu antes.

O próximo passo, nas tarefas, é a transição para uma nova base (para uma atividade conjunta) para atribuir significado à situação. 
3) Anotar em uma lista o maior número possível de diferentes palavras relacionadas à história comum desenhada;

4) trocar a lista de palavras com o parceiro e, utilizando as palavras da lista recebida, inventar uma frase bem longa;

5) contar a quantidade de palavras na frase inventada e comparar para verificar quem conseguiu utilizar o maior número de palavras da lista. Repassar essa frase mais longa a outro par (adulto-criança);

6) propor à criança que leia a frase formada.

Juntamente com o responsável, inventar uma nova frase que possa, por seu sentido, dar sequência à que foi lida, anotá-la e fazer as folhas circularem para dar continuidade ao texto dos demais participantes e, assim por diante, até a folha retornar ao mesmo par. Ler em voz alta o texto obtido.

7) Inventar um desafio para o desenho (pode ser um desafio, um verso, pode ser desenhar algo que não existe ou juntar alguns desenhos num único cenário, etc.).

Com esse exemplo é possível observar que a situação de relação de convivência do adulto com a criança da primeira idade escolar pode ser transformada em meio de desenvolvimento de estruturação da iniciativa, mantendo a relação de convivência com a criança em diferentes posições (acima, abaixo, de igual para igual e de "proto-nós"), valendo-se das aquisições da atividade de estudo.

O recurso diagnóstico desse exercício é: podemos observar a posição predominante que o adulto assume na relação de convivência, qual posição a criança dominou e quais ainda precisa dominar. Também é possível definir como a criança organiza seu sistema de tomada de consciência, como age, apoiando-se na imaginação (a neoformação do período pré-escolar) ou na estruturação voluntária (neoformação da primeira idade escolar). Também é possível observar se o adulto domina o conhecimento para encontrar novas bases para a atividade conjunta no mesmo conteúdo contextual. A situação para a estruturação voluntária surge quando alguma parte do conteúdo da relação de convivência (do que está no fundo) torna-se o momento determinante e central para a atividade conjunta e, posteriormente, ocorre novamente a troca de figura e fundo e a escolha de um novo destaque da base da relação mútua.

Ao nos reportarmos à lógica geral do desenvolvimento cultural da criança, é possível dizer que essa estruturação da iniciativa é um meio cultural e, ao dominá-lo, a criança começa a tomar consciência de si como sujeito de sua atenção, adquirindo um meio de controle da figura-fundo. A estruturação voluntária (a atenção voluntária) reestrutura também o funcionamento da memória, quando a criança, ao final da primeira idade escolar, pode fazer da figura um meio de assimilação da memorização e constrói sua história, generalizando suas próprias lembranças.

Fractal, Rev. Psicol., v. 32 - n. esp., p. 239-242, 2020
A atividade de estudo, como atividade-guia na primeira idade escolar, com sua estrutura muito precisa e rígida, permite desenvolver objetivamente a estruturação da iniciativa e, ao final dessa idade, a criança experimenta o novo meio cultural com o recurso que passou a controlar.

Pois bem, a nosso ver, a realização da abordagem histórico-cultural na prática do auxílio psicológico começa com a análise interna por parte do psicólogo dos próprios meios-instrumentos culturais, pela definição das próprias possibilidades e limitações no desenrolar de determinada função volitiva da consciência (como está estruturada minha fala, minha imaginação, minha atenção voluntária, o pensamento reflexivo).

É importante não apenas compreender as regularidades de constituição dessas neoformações psicológicas da idade na criança, como também diagnosticar os déficits que estão presentes nos adultos próximos.

$\mathrm{O}$ aspecto corretivo se constitui dos seguintes momentos centrais:

1) garantir a diversidade de posições da relação de convivência do adulto com a criança e do contexto dessa relação;

2) atualizar a capacidade do adulto de desvelar, demonstrar o meio cultural que define a linha central do desenvolvimento volitivo da personalidade, numa determinada idade psicológica;

3) enriquecer o conteúdo do tipo de atividade-guia que define a zona de desenvolvimento iminente da neoformação psicológica da idade.

A dinâmica desses três momentos permite estruturar um prognóstico provável, encontrar caminhos possíveis e direcionar a relação do psicólogo com a unidade comum "adulto-criança".

A relação mútua entre as crianças com diagnóstico de desequilíbrio no desenvolvimento psicológico, cultural e fisiológico e os adultos próximos é enriquecida pela utilização desses tipos de atividade que, em primeiro lugar, dão suporte à zona de desenvolvimento iminente das neoformações psicológicas da idade. No acompanhamento psicológico da criança, o psicólogo que se apoia na metodologia da abordagem histórico-cultural mantém como tarefa prioritária a ampliação das possibilidades dos responsáveis pela criação da zona de desenvolvimento iminente da criança.

\section{Informações sobre a autora:}

\section{Elena Gorlova}

iD https://orcid.org/0000-0002-6608-2964

(9. http://npsyj.ru/author/detail.php?Author=4717

PhD em Psicologia, professora associada do Departamento de Psicologia Especial do Instituto L. S. Vigotski da Universidade Russa de Humanidades. Seus interesses científicos estão relacionados à realização da abordagem histórico-cultural na prática do apoio psicológico à família. Elaborou e implementou diversos programas para a preparação das crianças para o ingresso na escola. É autora de 30 publicações. 


\section{Como citar este artigo:}

\section{ABNT}

GORLOVA, Elena. O olhar estereoscópico para a ontogênese: desafiando o professor. Fractal: Revista de Psicologia, Niterói, v. 32, n. esp., p. 239-242, jun. 2020. https://doi.org/10.22409/19840292/v32_i-esp/40987

\section{APA}

Gorlova, E. (2020, Junho). O olhar estereoscópico para a ontogênese: desafiando o professor. Fractal: Revista de Psicologia, 32(esp.), 239-242. doi: https://doi.org/10.22409/1984-0292/v32_iesp/40987

\section{Copyright:}

Copyright (C) 2020 Gorlova, E. Este é um artigo em acesso aberto distribuído nos termos da Licença Creative Commons Atribuição que permite o uso irrestrito, a distribuição e reprodução em qualquer meio desde que o artigo original seja devidamente citado.

Copyright (C) 2020 Gorlova, E. This is an Open Access article distributed under the terms of the Creative Commons Attribution License, which permits unrestricted use, distribution, and reproduction in any medium, provided the original article is properly cited.

\section{Referências}

KRAVTSOV, Guennadi. Problema litchnosti v kulturno-istoritcheskoi psirrologuii $[\mathrm{O}$ problema da personalidade na psicologia histórico-cultural]. Kulturnoistoritcheskais psirrologuia, Moskva, n. 1, p. 18-25, 2006.

KRAVTSOV, Guennadi. Ontoguenez voli [A ontogênese da vontade]. Vestnik RGGU, Moskva, n. 15, p. 29-41, 2012.

KRAVTSOVA, Elena; KRAVTSOV, Guennadi; BEREJKOVSKAIA, Elena. Programa vospitania detei mladchego i dochkolnogo vozrasta "Zolotoi kliutchik" [Programa de educação de crianças da creche e da pré-escola "Chave de ouro"]. Moskva: Izdatelstvo Lev, 2007.

VIGOTSKI, Lev Semionovitch. Problema razvitia vischikh psirritcheskih funktsi [O problema de desenvolvimento das funções psíquicas superiores]. In: IAROCHEVSKI, M. G. (Org.). Psirrologuia razvitia kak fenômeno kulturi [A psicologia do desenvolvimento como fenômeno cultural]. MoskvaVoronej: Izdatelstvo Institut praktitcheskoi psirrologuii - NPO Modek, 1996a.

VIGOTSKI, Lev Semionovitch. Lektsii pó pedologuii [Aulas de Pedologia]. Ijevsk: Izd-vo Udmurskogo Um-ta, 1996b. 